\title{
Optimizing the Protection Against the Physiological Burden of CBRN Clothing
}

\author{
Paul Brasser \\ TNO Defence, Security and Safety, The Netherlands
}

\begin{abstract}
Soldiers can wear chemical, biological, radiological and nuclear (CBRN) protective clothing to be protected agaist warfare agents. The disadvantage of that clothing is that higher protection introduces higher physiological burden. Therefore an optimum between comfort and protection must be found. Models of all relevant processes were created to find this optimum. The airflow profile around a cylinder with clothingrepresenting a dressed human body part-was modelled. This flow profile was used for calculating the agent vapour breakthrough through the clothing and for calculating the deposition of agents onto the skin (as indicators for protection). The flow profile was also used for calculating the temperature profile around the body part and the relative humidity underneath and in the clothing (as representative for physiological burden). As a result a tool was created, which can be used to identify the optimum properties of CBRN protective clothing, depending on the intended mission of the soldiers.
\end{abstract}

protective clothing protection CBRN physiological burden NBC temperature relative humidity vapour air velocity deposition model breakthrough permeable whole system cylinder optimize mission specific

\section{INTRODUCTION}

Soldiers can experience the threat of chemical warfare agents, when working in the field. To protect themselves against these vapours or liquids, they can wear chemical, biological, radiological and nuclear (CBRN) protective clothing. The CBRN protective clothing, currently in use by military forces, is usually an airpermeable carbon-based garment. The basis of the protection is adsorption of the toxic agent onto the carbon. The use of air-permeable materials in clothing reduces the thermal load offered by the clothing, by allowing air to flow through the material. However, at the same time the airflow can transport the toxic agents through the clothing, if the agent is not fully adsorbed by the carbon.

A way to identify the balance between physiological burden and protection is by modelling the important processes at hand and using these models to find the optimum.
The system requirements following from this optimization will lead to requirements for subsystems and materials of the clothing. That way a simulation tool will be created, which can be used by several different types of users, e.g.,

- military planners for identifying the ideal suit for a specific mission;

- producers of CBRN clothing for creating the optimum clothing design;

- researchers for finding the ideal balance between physiological burden and protection;

- quality testing for identifying key parameters.

To model the protective performance of airpermeable CBRN suits, several scales in the model have to be considered. Figure 1 illustrates the three scales:

- micro scale: the protective performance of the material itself;

Correspondence and requests for offprints should be sent to Paul Brasser, Bleijenburg 144, 2678 BD De Lier, The Netherlands. E-mail: <brasser@wanadoo.nl>. 
- meso scale: the effect of air flow around body parts on the deposition on the skin;

- macro scale: the model of the whole system (suit).

To model all the processes which occur underneath clothing in full detail, computational fluid dynamics (CFD) is required. For instance, the modelling of the air flow distribution around cylinders was described by using CFD [1, 2, 3, $4,5,6,7]$. Previously the micro-scale processes with respect to protection were studied [8]. Furthermore parameters like the air velocity distribution, the concentration distribution and the temperature distribution were analysed previously. Several types of turbulence models were examined. Figure 2 shows an example of

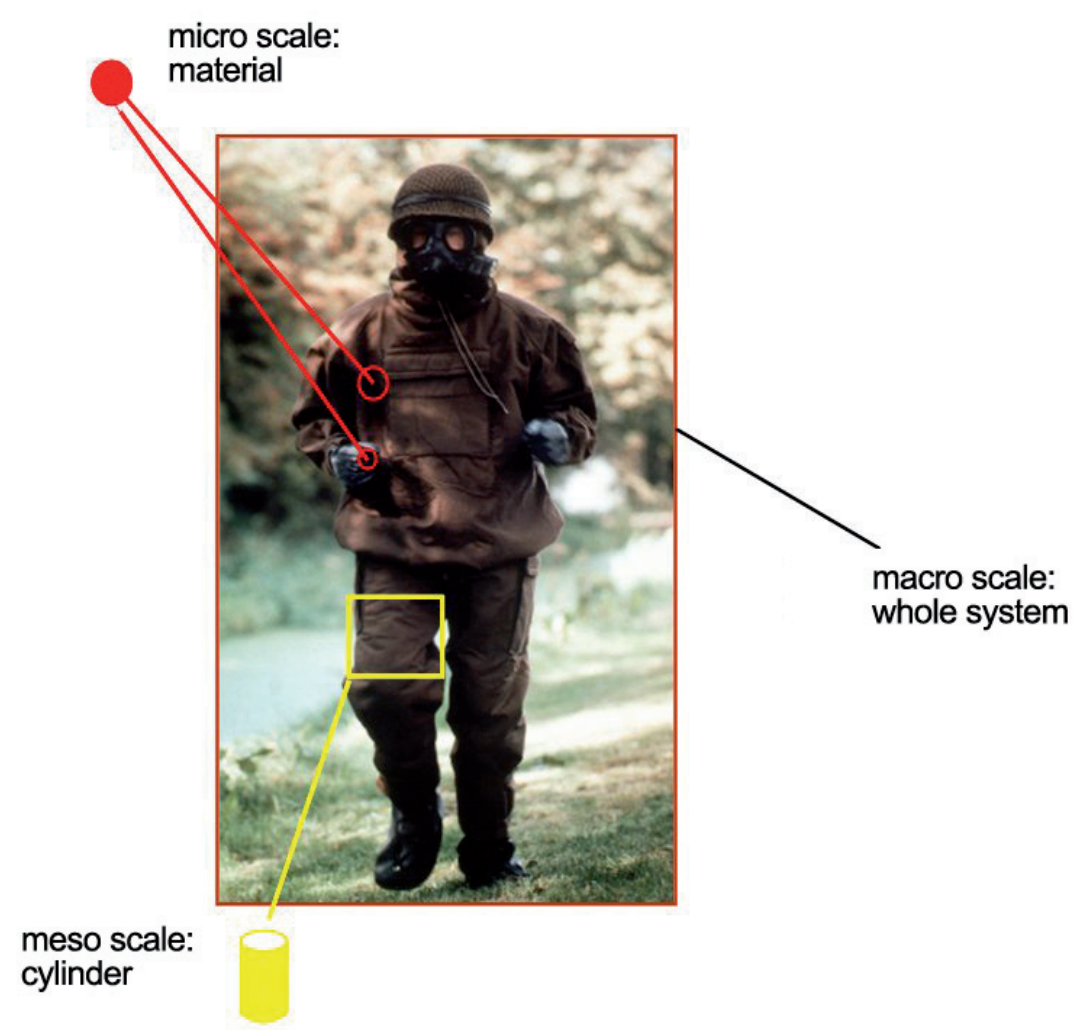

Figure 1. The process scales, important for the protection of a chemical, biological, radiological and nuclear (CBRN) suit.

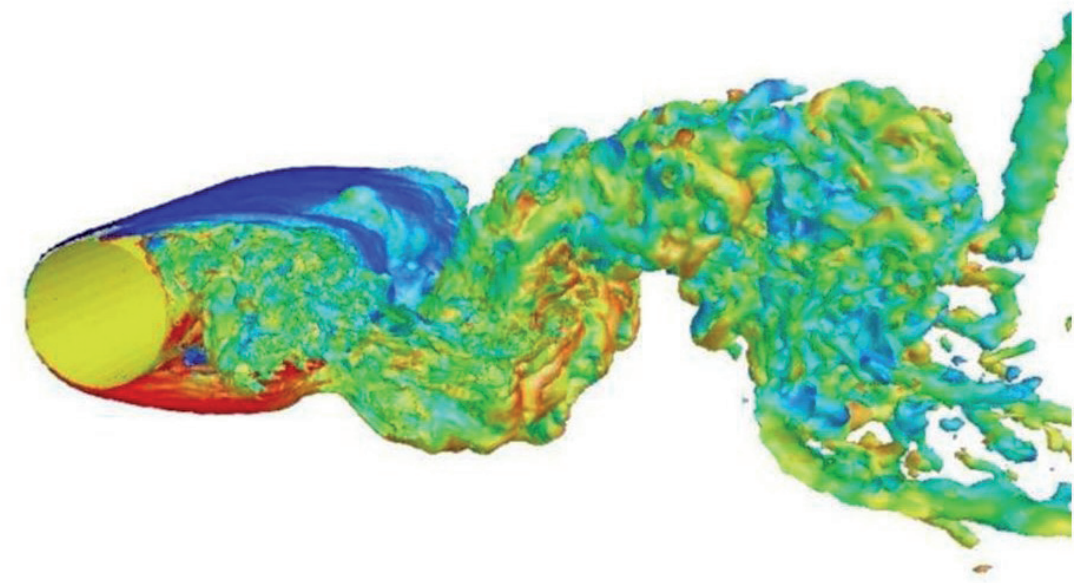

Figure 2. Computational fluid dynamics (CFD) calculations (direct numerical simulation, DNS) of the airflow around a cylinder. 
the results of the very time-consuming DNS (direct numerical simulation) calculations. A three-dimensional flow profile around a cylinder is shown. Behind the cylinder the (oscillating) wake of the air flow can be seen. This figure is a snap shot of a 16-s movie, which took 2 weeks to calculate.

It is convenient to have a model, which can predict the behaviour of these processes without using CFD, without high loss of accuracy. This is so, because of integration with other models; ease of use; ease of changing parameters; calculation time (when, e.g., DNS is used); etc. Therefore all these processes have to be modelled with basic one-dimensional physical transport equations [8, $9,10]$.

\section{PROCESSES}

Several processes occur when protective clothing is worn. To investigate both protective performance and comfort parameters, the following processes can be identified:

- air flow around, through and underneath the clothing;

- agent vapour breakthrough through the clothing;

- agent vapour concentration underneath the clothing;

- agent deposition onto the skin;

- water vapour penetration through the clothing;

- water vapour concentration underneath the clothing;

- evaporation and condensation of water from/in the clothing and from/onto the skin;

- temperature distribution through the clothing, underneath the clothing;

- skin temperature and core temperature;

- adsorption and absorption processes for agent and water in the clothing.

\subsection{Agent Vapour Breakthrough Through Clothing}

If the flow distribution around, through and underneath the clothing is known, a concentration distribution can be derived. The first step will be to calculate the agent vapour breakthrough through the protective clothing.

A model was derived earlier, which describes the vapour breakthrough through CBRN clothing as a function of time [8]. Only CBRN protective clothing materials of the carbon bead type have been taken into account. In this type of protective clothing chemical filtration is based on a single layer of small activated carbon spheres adhered to a carrier fabric. When an activated carbon filter is challenged by a chemical agent vapour flow, the breakthrough curve of the effluent concentration against time is typically $\mathrm{S}$-shaped. Typical for carbon bead type fabrics is an initial step in the breakthrough curve. Immediately after exposure a very small breakthrough concentration occurs that is roughly constant over a certain period of time (typically a few hours for CBRN clothing material).

\subsection{Air Flow Model}

A model was developed earlier, which describes pressure distribution and velocity through and underneath the clothing around the cylinder [9]. To model air flow distribution around a human limb, a simplification has been made by assuming this to be a two-dimensional problem. The body part is represented by a cylinder which is placed in airflow. At the front of the (dressed) cylinder the wind will penetrate the clothing and at the back it will flow back to the environment. If only homogeneous perpendicular flow of the outside wind is assumed and the air flow underneath the clothing is modelled only one-dimensionally, the process can be solved without using CFD. Figure 3 shows a schematic picture of the set-up.

The wind is blowing against the clothing around the cylinder with a velocity $v_{0}$. At the front of the cylinder, at point $\mathrm{C}$ (the stagnation point) the wind will partly flow through the porous clothing and will continue to flow underneath the clothing. At different points around the cylinder (different angles from the stagnation point, e.g., A), the velocity through the clothing will be different, because the pressure around the cylinder varies. Up to a certain angle, the wind will flow into the air gap, but at larger angles, the wind will flow out again. This process depends on the pressure in the 


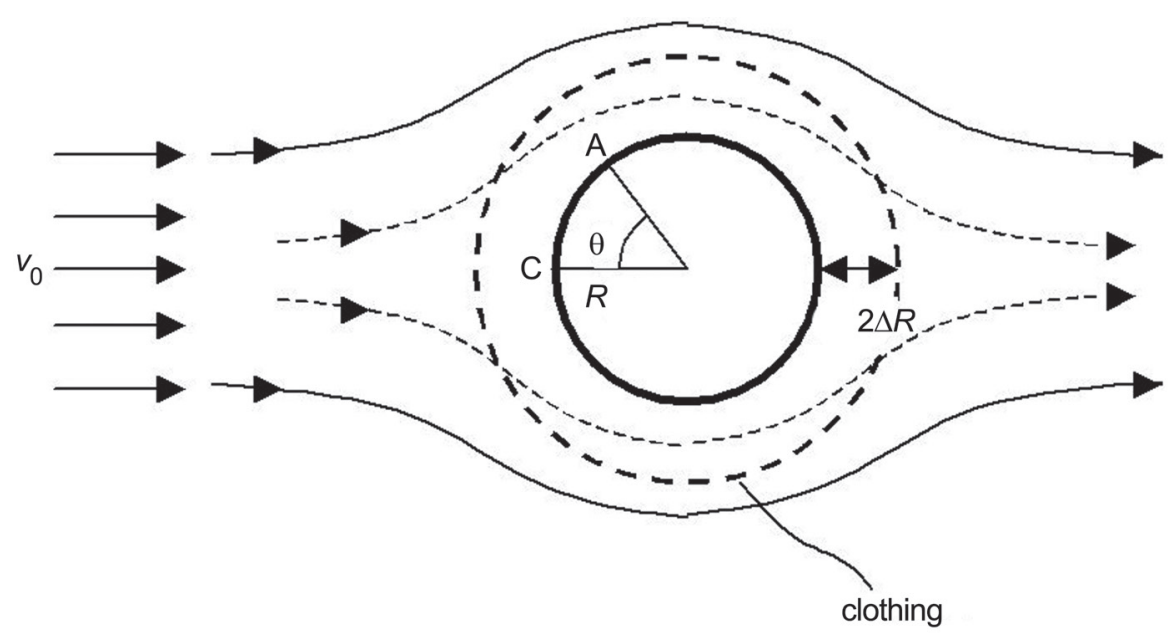

Figure 3. A schematic representation of a body part dressed in clothing, with airflow around and underneath the clothing. Notes. A, C-stagnation points; cf. p. 167-8 for definitions of the other symbols.

air gap underneath the clothing, which is also a function of the position around the cylinder.

\subsection{Agent Vapour Concentration and Deposition Model}

The breakthrough concentration model and the airflow distribution model can be used as input in the next step to model the concentration distribution underneath the clothing and the local mass deposition on the cylindrical surface. A model was developed earlier, which describes the vapour concentration underneath the clothing and the deposition onto the cylinder [10]. For this step it is assumed that (a) all the mass of the chemical agent which reaches the cylinder surface is adsorbed, and (b) the mass transport to the surface is described by the penetration theory $[11,12]$.

The first assumption implies that the concentration on the surface of the cylinder is always zero. A continuity equation (a mass balance for a slice of air underneath the clothing) describes the agent vapour concentration underneath the clothing as a function of the angle $\theta$ with respect to the wind direction around the cylinder (Figure 4).

\subsection{Moisture and Temperature Profile Model}

The water vapour concentration can be described similarly to the agent vapour concentration (Figure 4). However some adaptations have to

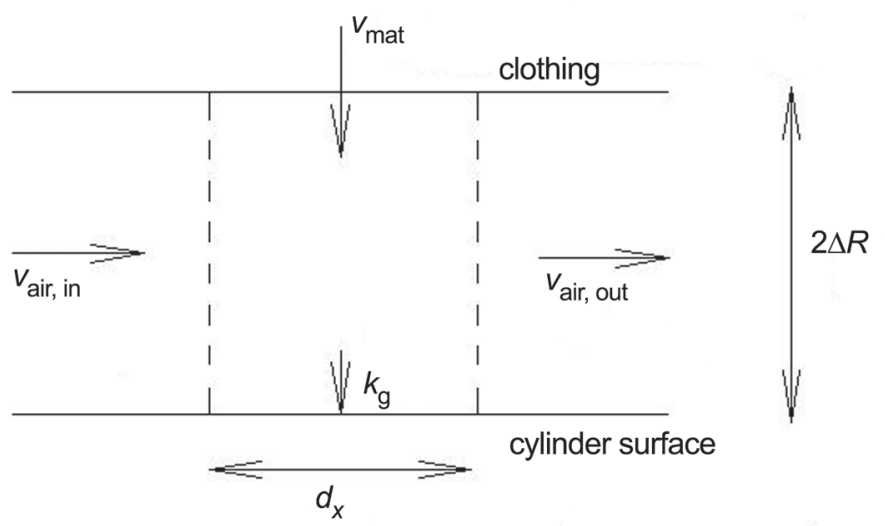

Figure 4. A volume element of air between the clothing and the surface of the cylinder. Notes. $d_{x}-$ tangential step along surface of cylinder (m); cf. p. 167-8 for definitions of the other symbols. 
be made onto the model. The main differences are (a) people sweat, thus the cylinder produces water vapour; and (b) water vapour can be absorbed in the clothing and can even condensate in the clothing or onto the skin, whereas the agent vapour adsorbs onto the adsorber (usually carbon).

A continuity equation (a mass balance for a slice of air underneath the clothing) describes the water vapour concentration underneath the clothing as a function of the angle $\theta$ with respect to the wind direction around the cylinder. A model was developed, which describes the humidity profile and temperature underneath the clothing.

\subsubsection{Moisture concentration and temperature underneath the clothing}

Analogous to the description of the agent vapour concentration in the air gap as described by Brasser and Houwelingen [10], the water vapour concentration, $C_{\mathrm{mi}}$, between the clothing, $C_{\mathrm{cl}}$, and the skin, $C_{\text {sk }}$, is also described with a continuity equation:

$$
\begin{gathered}
\frac{d C_{\mathrm{mi}}}{d t}=\frac{D}{R^{2}} \frac{d^{2} C_{\mathrm{mi}}}{d \theta^{2}}-\frac{v_{\mathrm{mi}}}{R} \frac{d C_{\mathrm{mi}}}{d \theta} \\
-\left(\frac{1}{2 \Delta R}\left(k_{1}+k_{2} f_{\mathrm{cl}}\right)+\frac{f_{\mathrm{cl}}}{2 \Delta R} v_{\mathrm{mat}}\right) C_{\mathrm{mi}} \\
+\frac{k_{1}}{2 \Delta R} C_{\mathrm{sk}}+\left(k_{2}+v_{\mathrm{mat}}\right) \frac{f_{\mathrm{cl}}}{2 \Delta R} C_{\mathrm{cl}} .
\end{gathered}
$$

Refer to p. 167-8 for definitions of the various symbols. The boundary conditions of this equation are

$$
\left.\frac{d C_{\mathrm{mi}}}{d \theta}\right|_{\theta=0}=\left.0 \quad \frac{d C_{\mathrm{mi}}}{d \theta}\right|_{\theta=\pi}=\left.0 \quad C_{\mathrm{mi}}\right|_{t=0}=0 .
$$

Similarly, the temperature in the air gap, $T_{\text {mi }}$, follows from

$$
\begin{aligned}
& \frac{d T_{\mathrm{mi}}}{d t}=\frac{a}{R^{2}} \frac{d^{2} T_{\mathrm{mi}}}{d \theta^{2}}-\frac{v_{\mathrm{mi}}}{R} \frac{d T_{\mathrm{mi}}}{d \theta} \\
& -\frac{1}{2 \Delta R}\left(h_{1}+h_{2} f_{\mathrm{cl}}+f_{\mathrm{cl}} v_{\mathrm{mat}}\right) T_{\mathrm{mi}} \\
& +\left(\frac{h_{1}}{2 \Delta R}\right) T_{\mathrm{sk}}+\frac{f_{\mathrm{cl}}}{2 \Delta R}\left(h_{2}+v_{\mathrm{mat}}\right) T_{\mathrm{cl}},
\end{aligned}
$$

with the boundary conditions

$$
\left.\frac{d T_{\mathrm{mi}}}{d \theta}\right|_{\theta=0}=\left.0 \quad \frac{d T_{\mathrm{mi}}}{d \theta}\right|_{\theta=\pi}=\left.0 \quad T_{\mathrm{mi}}\right|_{t=0}=T_{\text {skin }} .
$$

The mass transfer coefficients $k_{1}$ and $k_{2}$ and the heat transfer coefficients $h_{1}$ and $h_{2}$ are calculated as described by Brasser and Houwelingen [10].

\subsubsection{Moisture concentration and temperature in the clothing}

Inside the clothing, the water vapour concentration, $C_{\mathrm{cl}}$, depends on the water vapour concentration in both the air gap, $C_{\mathrm{mi}}$, and the environment, $C_{\mathrm{a}}$. Water can also absorb in the textile or even condensate:

$$
\begin{aligned}
\frac{d C_{\mathrm{cl}}}{d t}= & \left(k_{2}-v_{\mathrm{mat}}\right) \frac{1}{d_{\mathrm{cl}}} C_{\mathrm{mi}}-\left(k_{2}+\frac{D}{d_{\mathrm{cl}}}\right) \frac{1}{d_{\mathrm{cl}}} C_{\mathrm{cl}} \\
& +\left(\frac{D}{d_{\mathrm{cl}}}+v_{\mathrm{mat}}\right) \frac{1}{d_{\mathrm{cl}}} C_{\mathrm{a}}-\Psi_{\mathrm{cl}} \frac{1}{d_{\mathrm{cl}}} .
\end{aligned}
$$

The temperature of the clothing, $T_{\mathrm{c}}$, also shows a similar relationship. An important effect in this case is that absorption or condensation of water will affect the temperature.

$$
\begin{aligned}
\frac{d T_{\mathrm{cl}}}{d t} & =\left(h_{2}-v_{\mathrm{mat}}\right) \frac{1}{d_{\mathrm{cl}}} T_{\mathrm{mi}}-\left(h_{2}+\frac{a}{d_{\mathrm{cl}}}\right) \frac{1}{d_{\mathrm{cl}}} T_{\mathrm{cl}} \\
& +\left(\frac{a}{d_{\mathrm{cl}}}+v_{\text {mat }}\right) \frac{1}{d_{\mathrm{cl}}} T_{\mathrm{a}}+\frac{Q_{\mathrm{v}}}{\rho c_{\mathrm{p}}} \Psi_{\mathrm{cl}} \frac{1}{d_{\mathrm{cl}}} .
\end{aligned}
$$

The parameter $\Psi_{\mathrm{cl}}$ describes the mass change of the water vapour as a result of absorption of condensation of water in the textile. Thus

$$
\Psi_{\mathrm{cl}}=\frac{d M_{\mathrm{cl}}}{d t},
$$

where $M_{\mathrm{cl}}$ is the mass of the total amount of water, bound to the clothing (in kilograms of water per square metre of clothing). An empirical relationship is known for the water vapour absorption onto textile:

$$
\begin{gathered}
M=0.55 \bullet 10^{-3} \\
W_{\mathrm{cl}} \operatorname{Reg}_{\mathrm{cl}} \frac{C_{\mathrm{cl}}}{C_{\max }}\left(\frac{1}{0.25+\frac{C_{\mathrm{cl}}}{C_{\max }}}+\frac{1}{1.25-\frac{C_{\mathrm{cl}}}{C_{\max }}}\right),
\end{gathered}
$$


where $W_{\mathrm{cl}}$ is the weight of the textile in units of $100 \mathrm{~g} / \mathrm{m}^{2}$. The regain of the cloth is Reg (in grams of water per $100 \mathrm{~g}$ of clothing), which is the absorbed mass at $65 \% \mathrm{RH}$ (relative humidity) [13].

As a result of the absorption or condensation of water in the textile, heat is released. An empirical relationship describes the formed heat, $Q_{\mathrm{v}}$, (in Joules) per kilogram of absorbed water:

$$
\begin{gathered}
Q_{\mathrm{v}}=2430 \bullet 10^{3} \\
+195 \bullet 10^{3}\left(1-\frac{C_{\mathrm{cl}}}{C_{\max }}\right)\left(\frac{1}{0.2+\frac{C_{\mathrm{cl}}}{C_{\max }}}+\frac{1}{1.05-\frac{C_{\mathrm{cl}}}{C_{\max }}}\right) .
\end{gathered}
$$

This relation is valid when the water vapour concentration in the clothing is below the saturated water vapour pressure. The amount of absorbed mass in time can be found by substituting Equation 8 in 7 :

$$
\begin{aligned}
& C_{\mathrm{cl}} \leq C_{\mathrm{max}}, \\
& \frac{d M}{d t}=0.55 \bullet 10^{-3} W_{\mathrm{cl}} \operatorname{Reg}_{\mathrm{cl}}\left(\frac{0.25}{\left(0.25+\frac{C_{\mathrm{cl}}}{C_{\max }}\right)^{2}}\right. \\
& \left.+\frac{1.25-2 \frac{C_{\mathrm{cl}}}{C_{\max }}}{\left(1.25-\frac{C_{\mathrm{cl}}}{C_{\max }}\right)^{2}}\right) \bullet\left(\frac{1}{C_{\max }} \frac{d C_{\mathrm{cl}}}{d t}-\frac{C_{\mathrm{cl}}}{C_{\max }^{2}} \frac{d C_{\max }}{d T} \frac{d T}{d t}\right) .
\end{aligned}
$$

When the water vapour pressure is higher than the maximum vapour pressure, condensation will occur. The amount of condensation is dependant on the maximum vapour concentration (see section 2.4.4.) and can be described with

$$
\begin{gathered}
C_{\mathrm{cl}}>C_{\max }, \\
\frac{d M}{d t}=d_{\mathrm{cl}}\left(\frac{d C_{\mathrm{cl}}}{d t}-\frac{d C_{\max }}{d t}\right) \\
=d_{\mathrm{cl}}\left(\frac{d C_{\mathrm{cl}}}{d t}-\frac{d C_{\max }}{d T} \frac{d T}{d t}\right) .
\end{gathered}
$$

Equations 13 and 14 can be combined into one equation:

$$
\Psi_{\mathrm{cl}}=\frac{d M_{\mathrm{cl}}}{d t}=H \frac{d T_{\mathrm{cl}}}{d t}+K \frac{d C_{\mathrm{cl}}}{d t}
$$

with

$$
\begin{gathered}
C_{\mathrm{cl}}>C_{\mathrm{max}}, \\
H=-d_{\mathrm{cl}} \frac{d C_{\max }}{d T}, \\
K=d_{\mathrm{cl}}
\end{gathered}
$$

$$
\begin{aligned}
& \begin{array}{c}
C_{\mathrm{cl}} \leq C_{\max } \\
H=-0.55 \bullet 10^{-3} W_{\mathrm{cl}} \operatorname{Reg}_{\mathrm{cl}}\left(\frac{0.25}{\left(0.25+\frac{C_{\mathrm{cl}}}{C_{\mathrm{max}}}\right)^{2}}\right.
\end{array} \\
& \left.+\frac{1.25-2 \frac{C_{\mathrm{cl}}}{C_{\max }}}{\left(1.25-\frac{C_{\mathrm{cl}}}{C_{\max }}\right)^{2}}\right) \frac{C_{\mathrm{cl}}}{C_{\max }^{2}} \frac{d C_{\max }}{d T} \\
& K=0.55 \bullet 10^{-3} W_{\mathrm{cl}} \operatorname{Reg}_{\mathrm{cl}}\left(\frac{0.25}{\left(0.25+\frac{C_{\mathrm{cl}}}{C_{\mathrm{max}}}\right)^{2}}\right. \\
& \left.+\frac{1.25-2 \frac{C_{\mathrm{cl}}}{C_{\max }}}{\left(1.25-\frac{C_{\mathrm{cl}}}{C_{\max }}\right)^{2}}\right) \frac{1}{C_{\max }}
\end{aligned}
$$

Equations $5-14$ can be used to calculate $\frac{d C_{\mathrm{cl}}}{d t}$ and $\frac{d T_{\mathrm{cl}}}{d t}$ for every time step. These values are then used to calculate the temperature and concentration in the clothing for the next time step.

\subsubsection{Skin moisture concentration and temperature}

The water vapour concentration on the skin, $C_{\text {sk }}$, depends on both sweat production, $\Psi_{\mathrm{sw}}$, and the water vapour concentration underneath the clothing, $C_{\mathrm{mi}}$. In the current model, $\Psi_{\mathrm{sw}}$ will be an input parameter, but in reality this value depends on thermoregulation [13, 14, 15]. Sweat in the form of liquid water is expressed as $\Psi_{\text {drip }}$. The resulting mass balance is 


$$
\frac{d C_{\mathrm{sk}}}{d t}=k_{1}\left(C_{\mathrm{mi}}-C_{\mathrm{sk}}\right)+\Psi_{\mathrm{sw}}-\Psi_{\mathrm{drip}},
$$

with the boundary condition that on $t=0$ the skin concentration will be $C_{\mathrm{sk}}=0$, and $\Psi_{\text {drip }}=0$.

While $C_{\text {sk }}$ is below the saturated vapour pressure, $C_{\max }$, the liquid sweat will be $\Psi_{\text {drip }}=0$. When according to Equation 20 the concentration $C_{\text {sk }}$ becomes higher than the saturated water vapour concentration, $C_{\max }$, the vapour concentration will be

$$
C_{\mathrm{sk}}=C_{\max }
$$

and

$$
\Psi_{\text {drip }}=\frac{D}{\delta_{1}}\left(C_{\text {mi }}-C_{\max }\right)+\Psi_{\text {sw }}
$$

\subsection{4. $R H$}

The moisture concentration, $C_{\text {moisture, }}$ is usually expressed as RH by making it dimensionless. The $\mathrm{RH}$ is calculated by

$$
R H=\frac{C_{\text {moisture }}}{C_{\max }} .
$$

The maximum water vapour concentration follows from the Antoine equation:

$$
C_{\max }=\frac{1}{461.4 T} \exp \left(23.5613-\frac{4030.183}{T-38}\right) .
$$

An interesting result of expressing the vapour concentration that way is that when the temperature changes but the water vapour concentration stays constant, the RH still changes.

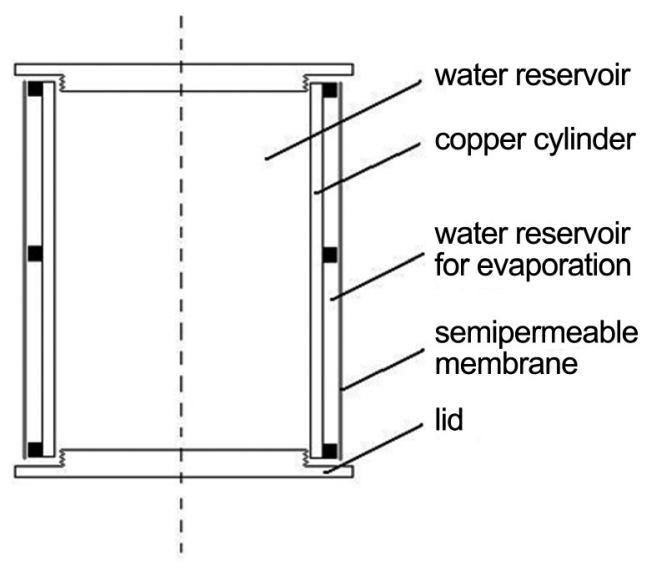

\section{EXPERIMENTS}

To validate the temperature and humidity models, a double walled cylinder was constructed, which can produce sweat. Both RH and the temperature can be measured underneath the clothing at several different angles around the cylinder. The cylinder is made of metal and can be filled with water (Figure 5). Inside this cylinder a heating element is placed. This heating element can heat the water inside the cylinder to a desired temperature (e.g., $37^{\circ} \mathrm{C}$ ). The temperature is monitored with an RTD (resistance temperature device) temperature probe, which is located in the space between the two walls. This space is also filled with water to conduct the temperature and to produce sweat. The outer wall is a semipermeable membrane. Liquid water cannot penetrate this membrane, but vapour water can. This way the creation of vapour sweat is simulated.

CBRN textile is wrapped around the cylinder at a defined distance from the membrane (the cylinder wall). Underneath this textile three RTD temperature probes are placed at the angles from the stagnation point of $22.5,90$ and $135^{\circ}$. $\mathrm{RH}$ is monitored with three Honeywell (USA) HIH-4000-003 relative humidity probes at the angles of 45,90 and $180^{\circ}$. Furthermore both the temperature and the $\mathrm{RH}$ of the environment were monitored as well. The whole apparatus is controlled with a USB DAQ device from

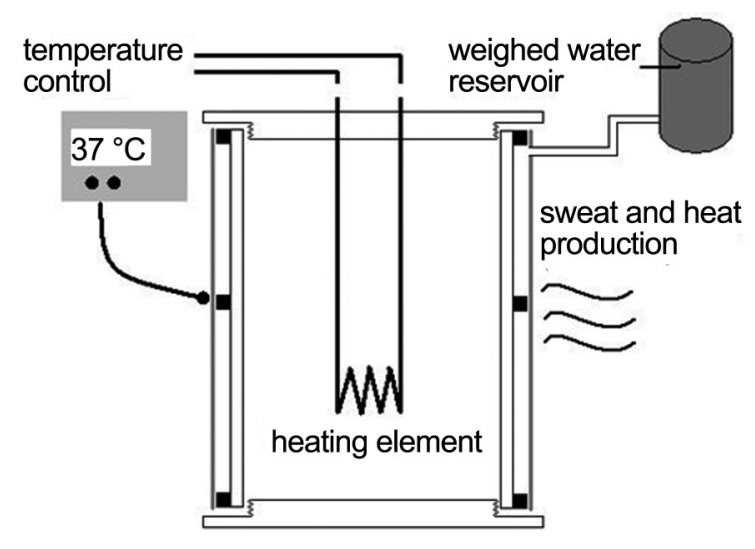

Figure 5. A schematic representation of the experimental set-up. 
National Instruments (USA), which is attached to a computer.

The wind speed was induced with a blower, which could blow at three different wind speeds (see section 4 for the exact values). The wind velocity is measured continuously during the experiment with a hot-wire anemometer. Two types of clothing were used, one with a low and another one with a high air resistance $(0.14$ and $\left.1.6 \mathrm{mmH}_{2} \mathrm{O} /(\mathrm{cm} / \mathrm{s})\right)$.

\section{RESULTS}

Before the actual tests were performed, the wind velocity was analysed. The wind velocity is reasonably constant over time $(\sim 5 \% S D)$. The average wind velocity, which was used in the experiments was $5.0 \pm 0.25 \mathrm{~m} / \mathrm{s}$.

\subsection{Temperature Profile}

Figure 6 shows temperature measurements underneath clothing of high air resistance as a function of time together with the calculated results. The calculated temperature values underneath the clothing material are in quite good agreement with the measured values. Figure 7 shows temperature measurements underneath clothing of high air resistance as a function of the angle around the cylinder together with the calculated results.

An interesting result, which follows from Figure 7 , is that the temperature will have a maximum value at a certain angle. Both the measurements and the calculations show such behaviour. The calculated temperature of the low air resistance material shows quite a similar behaviour as the measurements though the maximum is found at a different angle. Different air permeability leads to a shift of the angle of the maximum air velocity, which in turn will affect the maximum of the temperature profile. The calculations underestimate the temperature of the low air resistant material. A reason for this difference can be that in reality the air gap size is smaller than the size used in the calculations. When the air gap is smaller, less air will penetrate the material. Thus less cold air from the environment will penetrate. As a result, the real air temperature will be higher. This effect will be smaller for low air permeable material, since the amount of penetrating cold environmental air will be lower because of the higher air resistance.

\subsection{RH Profile}

Figure 8 shows RH measurements underneath clothing of both low and high air resistance as a

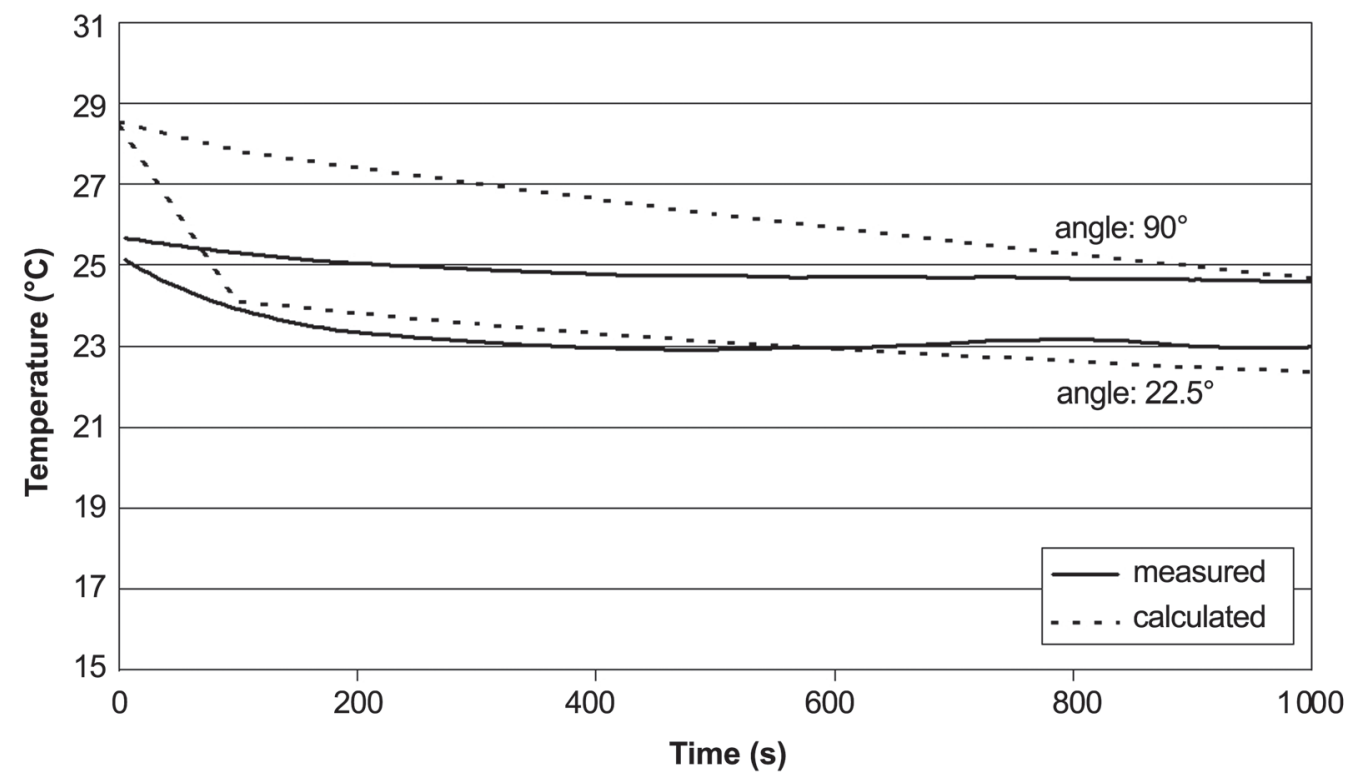

Figure 6. Temperature measurements underneath clothing of high air resistance as a function of time at two different angles around the cylinder. 


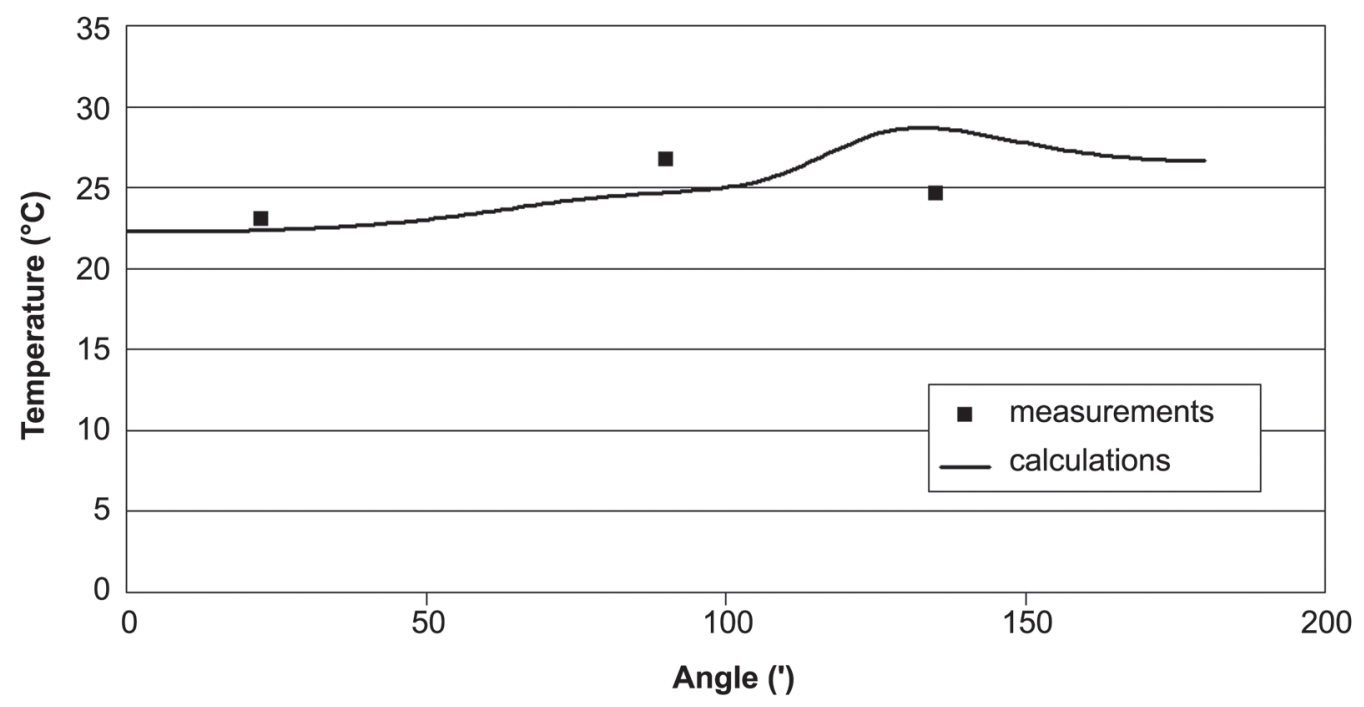

Figure 7. Temperature measurements underneath clothing of high air resistance.

function of the angle around the cylinder together with the calculated results. The calculated values of the RH for high air resistant material are in better comparison to the experiments (but not good) than the results for low air resistant material. The measured $\mathrm{RH}$ for high air permeable material is always higher than the values for low air permeable material. This was not expected, since low air resistant material would allow more air from the environment to flow in (which has a lower RH). It is advisable to repeat these measurements in the future to see if this behaviour was correctly analysed.

\section{DISCUSSION}

To find an optimum balance between physiological burden and protection, profiles of the various processes have to be calculated and analysed simultaneously [16]. In this section several cross linking parameter studies are described. This will result in section 5.3. which will focus on finding the optimum between ventilation and protection.

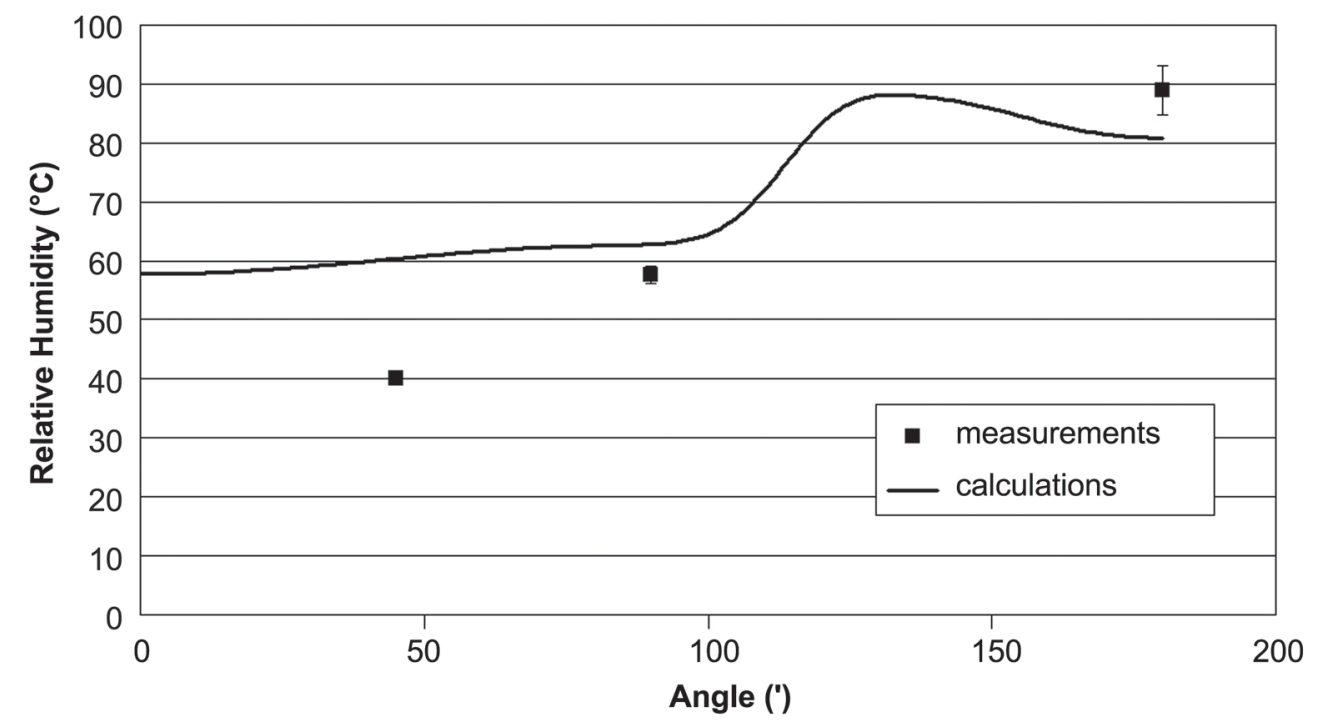

Figure 8. Relative humidity measurements underneath clothing of high air resistance. 


\subsection{The Offered Protection}

To analyse whether the clothing material offers enough protection during an experiment, the breakthrough through the clothing material was calculated for every angle around the cylinder, taking into account the air velocity through the material at every specific angle. This breakthrough was studied in time. Figure 9 shows breakthrough calculations. The curve at the back is the initial breakthrough and every next curve is $10000 \mathrm{~s}$ further in time.

After several hours the back side of the cylinder still offers enough protection, but the front of the cylinder will increase because the adsorption

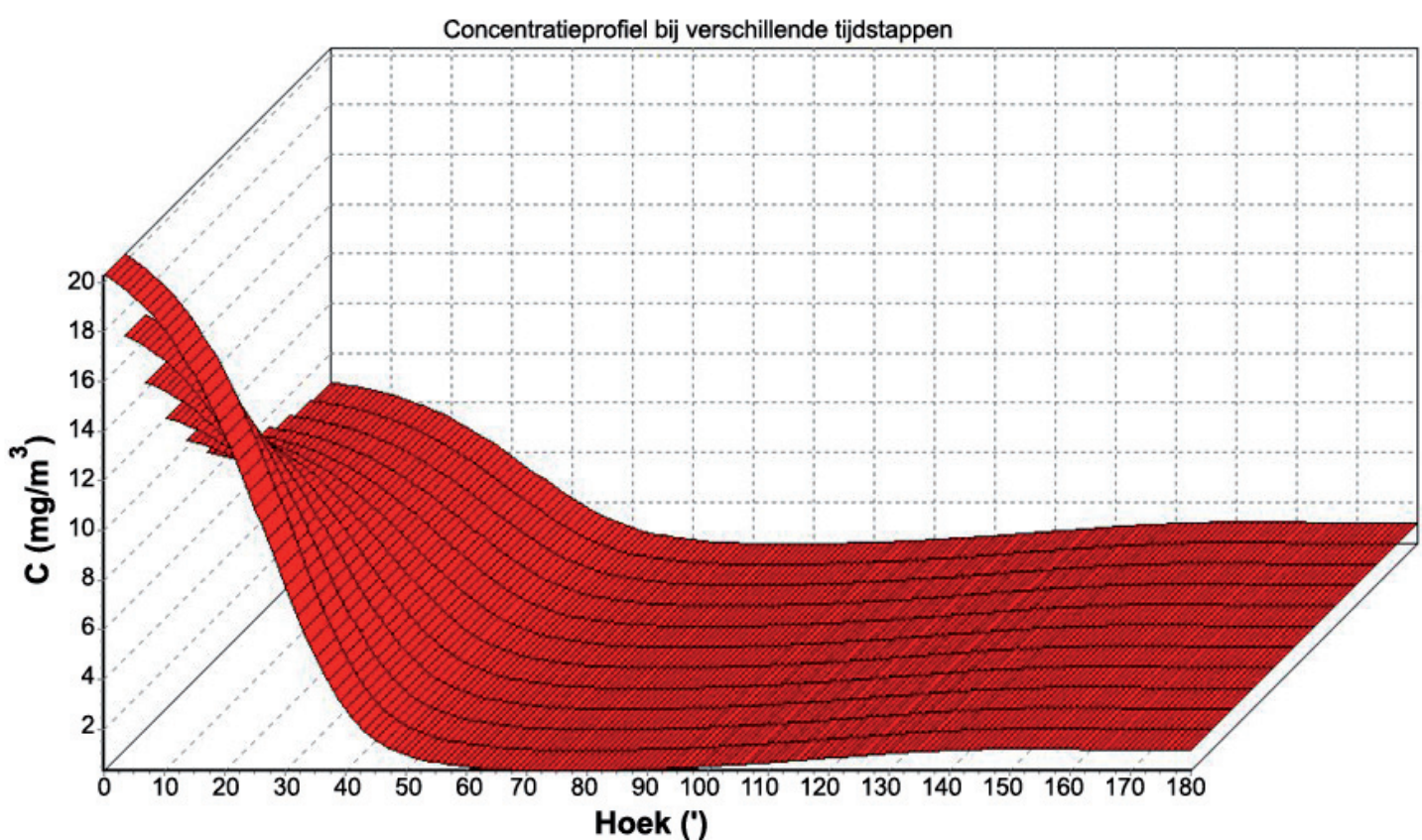

Figure 9. Program output (in Dutch, saying "concentration at various time steps"), showing the breakthrough of vapour through clothing material around the cylinder. The curve at the back is the initial breakthrough and every next curve is $10000 \mathrm{~s}$ further in time.

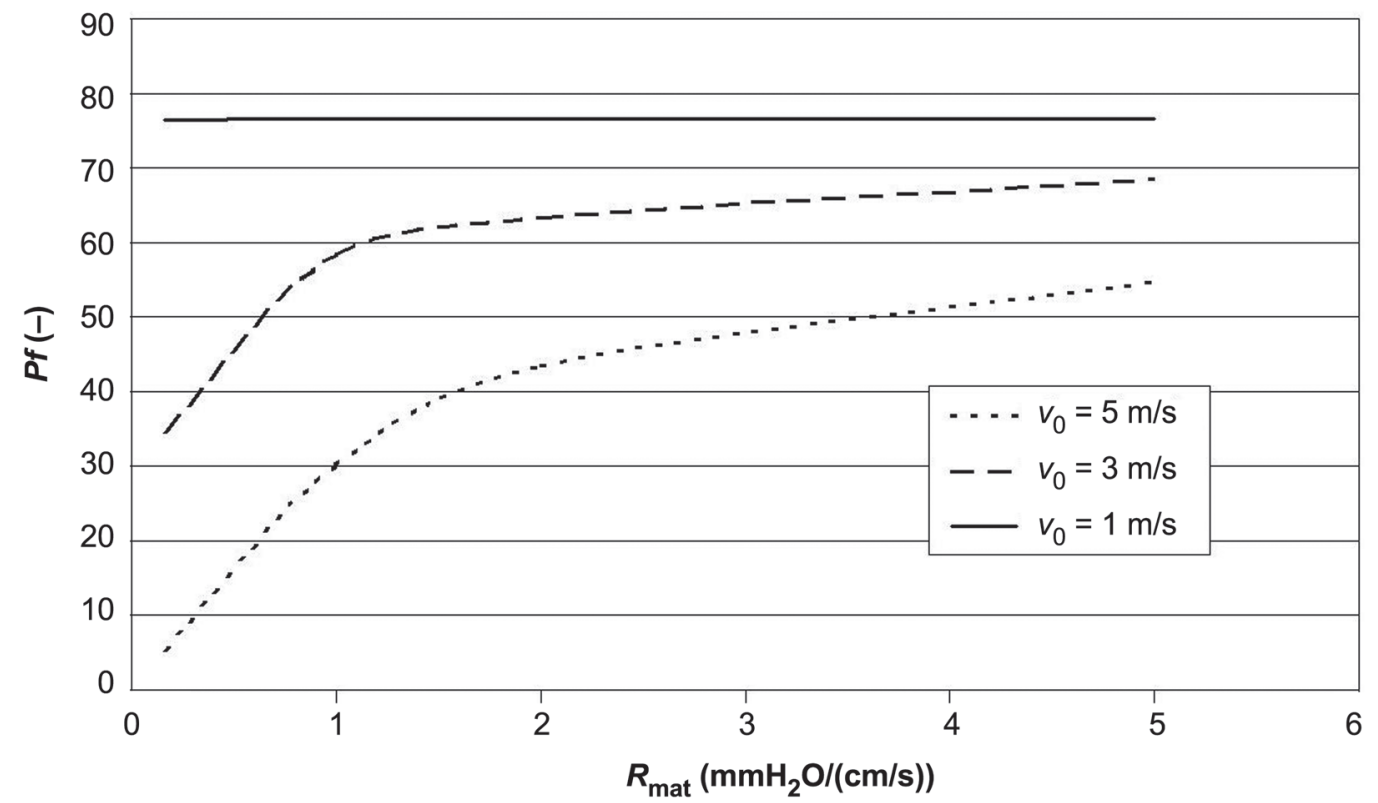

Figure 10. The calculated protection factor $(P f)$ as a function of the air resistance of the clothing $\left(\boldsymbol{R}_{\text {mat }}\right)$. Notes. $v_{0}$-wind velocity. 
capacity of the carbon is reached. The protection factor of the material can be defined as the environmental agent concentration, divided by the average concentration underneath the clothing. In Figure 10 the calculated protection factor is plotted as a function of the air resistance of the clothing. The protection factor of the clothing increases as a function of the air resistance of the clothing.

The air gap size will have an effect on the protection factor. Figure 11 shows this effect. The protection increases when the air gap size decreases. This means that, e.g., a protecting undergarment will offer a better protection, even when the air resistance stays the same because the air gap size is very small.

\subsection{The Physiological Burden}

The degree of physiological burden depends on parameters such as the skin and core temperature and the moisture concentration and the air velocity underneath the clothing. The effect of the air resistance of the clothing on these parameters was studied.

\subsubsection{Air velocity in the air gap}

For the velocity through the clothing, the average inward velocity through the clothing was taken, which is the average value between 0 and $45^{\circ}$ [9]. The average velocity underneath the clothing was also a parameter. Figure 12 shows the average velocity through and underneath the clothing, as a function of the air resistance of the clothing.

As expected, both the average velocity through the clothing and underneath the clothing decreases with increasing air resistance (decreasing air permeability) of the clothing. Since lower air velocity is considered to increase the physiological burden in this paper, the physiological burden increases with increasing air resistance of the clothing.

Calculations also showed that the air velocity through the clothing will increase with increasing air gap size. This indicates that a protecting undergarment will offer less ventilation and thus will pose a higher physiological burden.

\subsubsection{Temperature in the air gap}

The average air gap temperature was calculated as a function of the air resistance of the material. To get insight into the effect of the environment, these calculations were performed at several environmental temperatures. The air gap temperature will increase with increasing air resistance of the clothing, thus as expected the

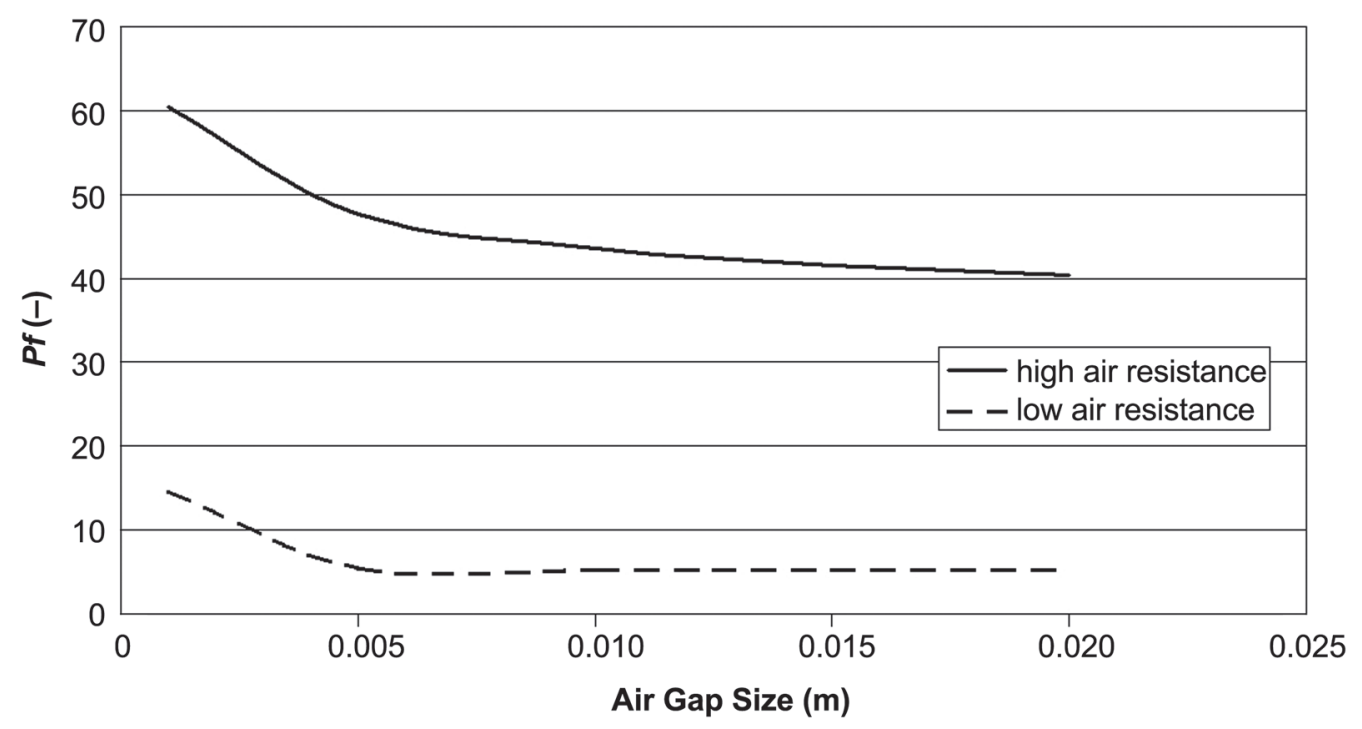

Figure 11. The calculated protection factor $(P f)$ as a function of the air gap size underneath the clothing for 2 different air resistances of the clothing. 


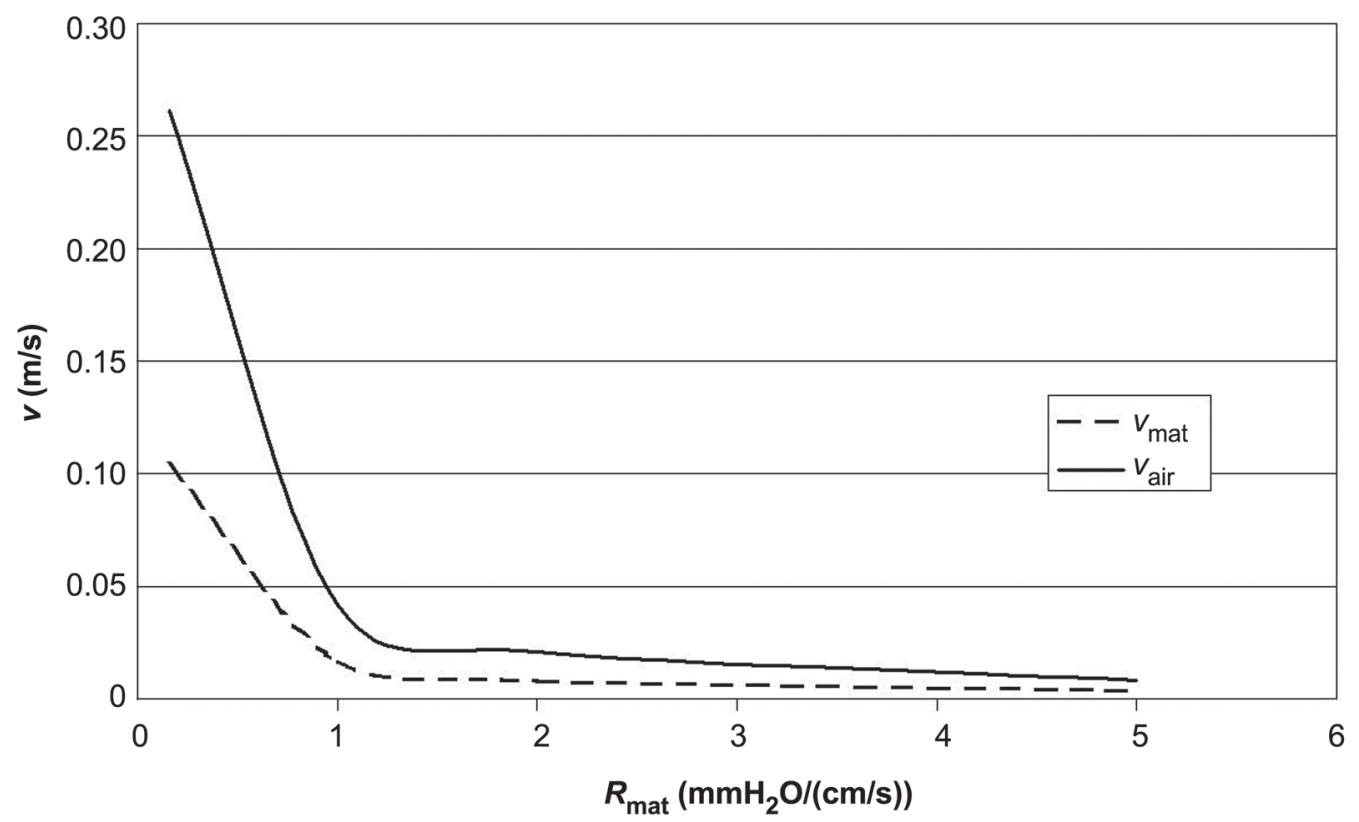

Figure 12. The average velocity $(v)$ through and underneath the clothing, as a function of the air resistance of the clothing $\left(\boldsymbol{R}_{\text {mat }}\right)$. Notes. $v_{\text {mat }}$-air velocity through clothing, $v_{\text {air }}$-air velocity in air gap.

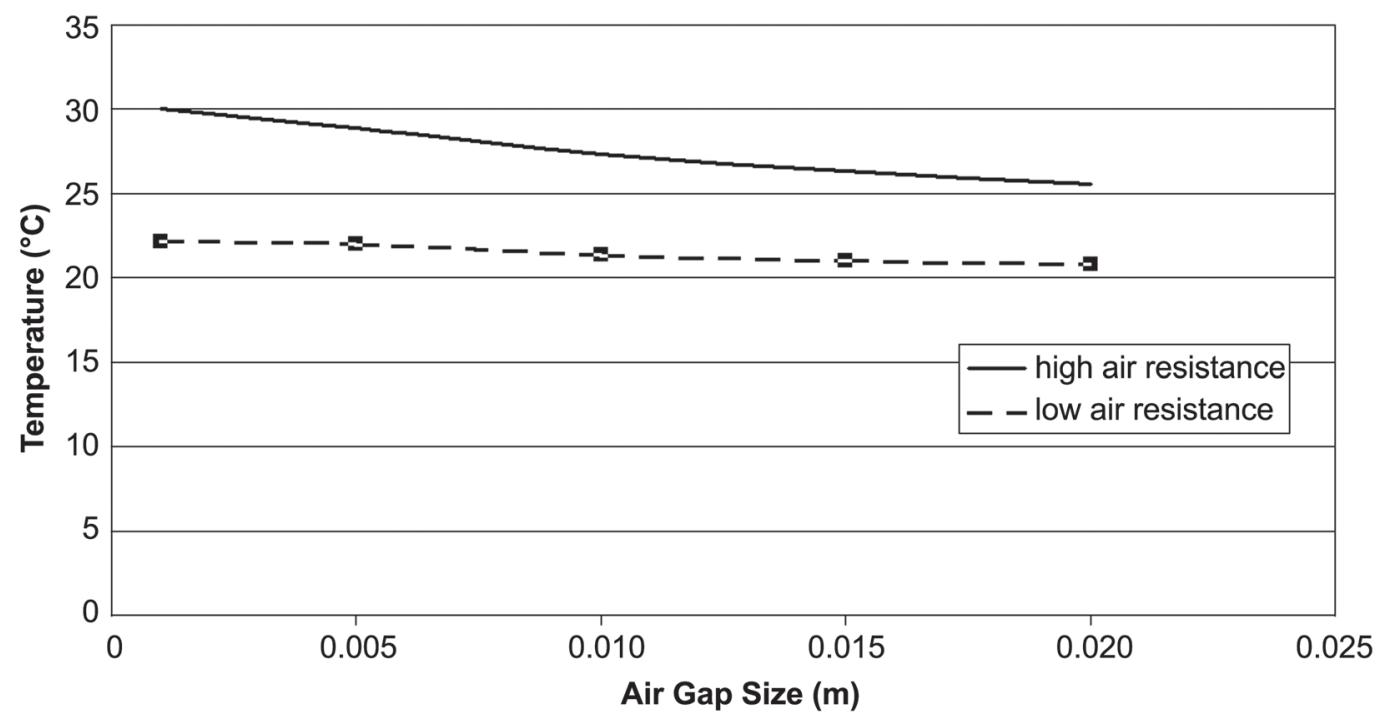

Figure 13. The average temperature underneath the clothing, as a function of the air gap size underneath the clothing for 2 air resistances of the clothing $\left(\boldsymbol{R}_{\text {mat }}\right)$.

physiological burden increases with increasing air resistance of the clothing.

Figure 13 shows the effect of the air gap size on the temperature underneath the clothing. Due to higher ventilation at larger air gap sizes, the temperature will decrease underneath the clothing. Thus a protecting undergarment (smaller air gap size) will create higher heat stress and a higher physiological burden.

\subsection{3. $R H$ in the air gap}

The average $\mathrm{RH}$ in the air gap was calculated as a function of the air resistance of the material. To get insight into the effect of the environment, these calculations were performed at both 20 and $40{ }^{\circ} \mathrm{C}$ (cf. Figure 14).

The RH underneath the clothing will increase with increasing air resistance of the clothing material, leading to a higher physiological burden. The average RH underneath the clothing 


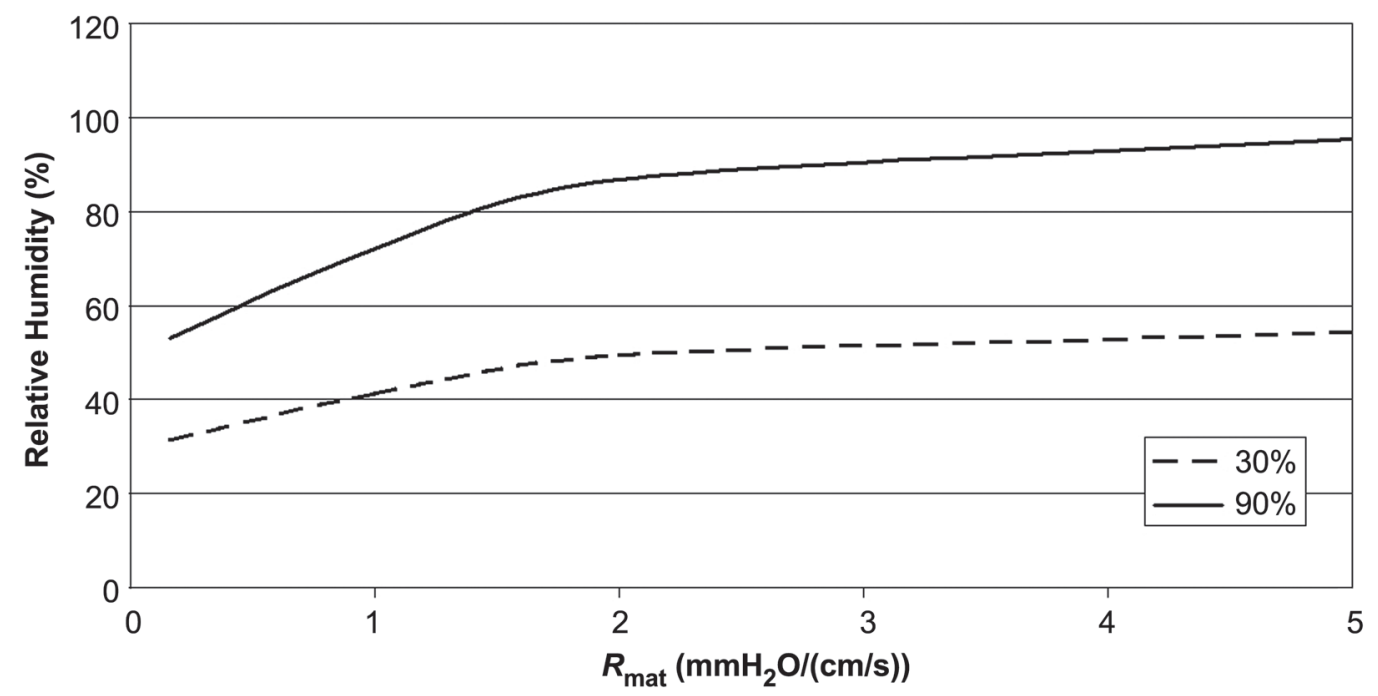

Figure 14. The average relative humidity underneath the clothing as a function of the air resistance of the clothing material $\left(\boldsymbol{R}_{\text {mat }}\right)$ for 2 environmental relative humidities (environmental temperature is $\left.20^{\circ} \mathrm{C}\right)$.

will be somewhat higher for high environmental temperatures. This also leads to a higher physiological burden.

\subsection{Optimization}

In the previous sections the effect of parameters like the air gap size and the air resistance of the clothing on both the protection and the physiological burden were analysed. The parameter study showed that a higher air resistance of the clothing resulted in a better protection, a lower air velocity in the air gap (thus a higher physiological burden), and a higher temperature and $\mathrm{RH}$ in the air gap (also leading to higher physiological burden).

The protection increases when the air gap size decreases. This means that, e.g., a protecting undergarment will offer a better protection, even when the air resistance stays the same. On the other hand the temperature underneath the clothing will increase, which will lead to a higher physiological burden.

Thus the protection and the physiological burden are oppositely affected by both the size of the air gap and the air resistance of the clothing. Higher protection will lead to higher physiological burden and vice versa. Thus the optimum between protection and physiological burden is mission dependent. Depending on the mission either the protection or the physiological burden has to be marked as more important, which will lead to other optima. The developed modelling tool can be used to identify the best optimum for each specific mission.

This optimization modelling tool can be useful in several different processes.

- Planning: a planner can use this tool to identify the best possible CBRN protective suit, depending on the mission, by taking into account both physiological burden and protection.

- Improving materials: at the moment material improvements for CBRN clothing are a trialand-error process. It will save both time and money to first identify the best potential material with this model, based on is properties, such as carbon properties, air resistance, moisture behaviour, etc.

- Designing prototypes: it is not only the material itself that is important for the protective performance of a CBRN suit, but so is the design, since processes such as bellowing and leakage have an effect on the air velocity and concentration. A whole system model could help in designing the optimum design and closures. 


\section{CONCLUSIONS}

A modelling tool is being developed; it can be used to optimize the physiological burden effects and protective performance of CBRN clothing around a cylinder. To identify the most adequate type of CBRN protective clothing, a compromise between physiological burden and protection has to be found. The current model focuses on temperature, $\mathrm{RH}$, air velocity and agent concentration underneath clothing around a cylinder.

As expected, better protection can only be created when a higher physiological burden is also tolerated. This means a different physiological burden is allowed for every mission, thus the protection will be mission dependant.

The current models do not yet include leakage of agent through, e.g., closures. When the models are extended toward a whole system, they can be used to create an optimum design of the suit. Closures and other leakages of agent will influence the concentration underneath the clothing and thus the total deposition onto the skin (and thereby the protection). Induced air pumping (or the bellowing effect) will affect the air velocity underneath the clothing and thus the physiological burden. When these aspects are modelled as well, a better optimum can be found.

Another missing part in the model is a body model, combined with a good sweat model. In the current model the body core temperature and the sweat rate are kept constant. This is not yet totally realistic. Therefore it is advisable to include such a model into the package. This is especially important when the whole system model is built.

\section{REFERENCES}

1. Sobera MP, Kleijn CR, Brasser P, Akker HEA van den. Heat and mass transfer to a cylinder surrounded by a porous material. In: Kleijn CR, Kawano S, editors. Proceedings of the ASME 4th International Symposium on Computational Technologies for Fluid/Thermal/Structural/Chemical Systems with Industrial Applications, Vancouver, BC, Canada (PVP-Vol. 448-1). New
York, NY, USA: ASME International; 2002. p. 249-60.

2. Sobera MP, Kleijn CR, Brasser P, Akker HEA van den. Forced flow heat and mass transfer to a cylinder surrounded by a porous material with applications to CBRN protective clothing. In: Kawano S, Kleijn CR, editors. Proceedings of the 2002 ASME Pressure Vessel and Piping Conference, Vancouver, Canada. 2002; 448(1):249-60.

3. Barry J, Hill R, Brasser P, Sobera MP, Kleijn CR, Gibson P. Computational fluid dynamic modeling of fabric systems for intelligent garment design. MRS Bull. 2003;28:568-73.

4. Sobera MP, Kleijn CR, Akker HEA van den, Brasser P. Convective heat and mass transfer to a cylinder sheathed by a porous layer. AIChE J. 2003;49:3018-28.

5. Sobera MP, Kleijn CR, Brasser P, Akker HEA van den. Multiscale CFD of the flow, heat and mass transfer through a porous materials with application to protective garments. In: Kawano S, Kleijn CR, Kudriavtsev V, editors. Proceedings of 2004 ASME Pressure Vessel and Piping Conference, San Diego, USA. 2004;491(1):187-96.

6. Sobera MP, Kleijn CR, Brasser P, Akker HEA van den. A multi-scale numerical study of the flow, heat, and mass transfer in protective clothing. LNCS. 2004;3039:637-44.

7. Gibson P, Barry J, Hill R, Brasser P, Sobera MP, Kleijn CR. Computer modelling of heat and mass transport in protective clothing. In: Pan N, Gibson P, editors. Thermal and moisture transport in fibrous materials. Cambridge, UK: Woodhead; 2006. p. 542-59.

8. Brasser P. Modeling the chemical protective performance of CBRN clothing material. J Occup Environ Hyg. 2004;1:620-8.

9. Brasser P. Theoretical and experimental study of airflow through clothing around body parts. AIChE J. 2006;52(11):3688-95.

10. Brasser $P$, Houwelingen $T$ van. A theoretical and experimental study of the vapour deposition onto the surface of a dressed body part. AIChE J. 2008;54(4):844-8. 
11. Smith JM, Stammers E, Janssen LPBM. Fysische transportverschijnselen I [Physical transport phenomena I]. Delft, The Netherlands: Delftse Uitgevers Maatschappij; 1997.

12. Lyklema J. Fundamentals of interface and colloid science. Volume 1: fundamentals. London, UK: Academic Press; 1991.

13. Lotens WA. Heat transfer from humans wearing clothing [doctoral dissertation]. Delft, The Netherlands: Delft University of Technology; 1993.

\section{SYMBOLS}

Roman alphabet

a thermal diffusivity

C concentration

$\mathrm{C}_{\mathrm{a}} \quad$ outside concentration

$C_{\mathrm{cl}} \quad$ moisture concentration in clothing

$C_{\text {ini }} \quad$ initial breakthrough concentration

$C_{\mathrm{mi}} \quad$ moisture concentration

$C_{\max } \quad$ maximum moisture concentration

$C_{\mathrm{p}} \quad$ specific heat of air

$C_{\mathrm{s}} \quad$ surface concentration

$C_{\text {sat }} \quad$ saturation concentration

$D \quad$ diffusion coefficient

$d_{\mathrm{cl}} \quad$ thickness of clothing material

$f_{\mathrm{cl}} \quad$ shapefactor

$H$ temperature effect of water absorption

$K \quad$ concentration effect of water absorption

$k_{\mathrm{g}} \quad$ mass transfer coefficient

$k_{1} \quad$ mass transfer coefficient

$k_{2} \quad$ mass transfer coefficient

$h_{1} \quad$ heat transfer coefficient

$h_{2} \quad$ heat transfer coefficient

$M \quad$ absorbed water mass

Pf protection factor

$R \quad$ radius of cylinder

$\mathrm{RH}$ relative humidity

$\Delta R \quad$ half size of air gap

Reg regain of the clothing

$R_{\text {mat }} \quad$ air resistance of clothing

$Q_{\mathrm{v}} \quad$ absorption heat

$t \quad$ time
14. Havenith G. Individual heat stress response [doctoral dissertation]. Nijmegen, The Netherlands: Catholic University Nijmegen; 1997.

15. Gagge AP, Fobelets AP, Berglund LG. A standard predictive index of human response to the thermal environment. ASHRAE Trans. 1986;92:709-31.

16. Brasser P. Modeling the relation between comfort and protection of CBRN-suits. In: Acosta JL, Camacho AF, editors. Porous media: heat and mass transfer, transport and mechanics. New York, NY, USA: Nova Science; 2009. $\left(\mathrm{m}^{2} / \mathrm{s}\right)$

$\left(\mathrm{kg} / \mathrm{m}^{3}\right)$

$\left(\mathrm{kg} / \mathrm{m}^{3}\right)$

$\left(\mathrm{kg} / \mathrm{m}^{3}\right)$

$\left(\mathrm{kg} / \mathrm{m}^{3}\right)$

$\left(\mathrm{kg} / \mathrm{m}^{3}\right)$

$\left(\mathrm{kg} / \mathrm{m}^{3}\right)$

$(\mathrm{J} / \mathrm{kgK})$

$\left(\mathrm{kg} / \mathrm{m}^{3}\right)$

$\left(\mathrm{kg} / \mathrm{m}^{3}\right)$

$\left(\mathrm{m}^{2} / \mathrm{s}\right)$

(m)

$(-)$

$(\mathrm{kg} / \mathrm{K})$

$\left(\mathrm{m}^{3}\right)$

$(\mathrm{m} / \mathrm{s})$

$(\mathrm{m} / \mathrm{s})$

$(\mathrm{m} / \mathrm{s})$

$(\mathrm{m} / \mathrm{s})$

$(\mathrm{m} / \mathrm{s})$

$(\mathrm{kg})$

$(-)$

(m)

(\%)

(m)

(g water/100 g clothing)

$\left(\mathrm{mmH}_{2} \mathrm{O} /(\mathrm{cm} / \mathrm{s})\right)$

$(\mathrm{J} / \mathrm{kg})$

(s) 
168 P. BRASSER

$T$ temperature (K)

$T_{\mathrm{cl}} \quad$ temperature in clothing $\quad(\mathrm{K})$

$T_{\mathrm{a}} \quad$ temperature in environment $\quad(\mathrm{K})$

$T_{\mathrm{mi}} \quad$ temperature underneath clothing $\quad(\mathrm{K})$

$v_{0} \quad$ wind velocity $\quad(\mathrm{m} / \mathrm{s})$
$\left.v_{\mathrm{a}}\right)$

$v_{\text {air }} \quad$ air velocity in air gap $\quad(\mathrm{m} / \mathrm{s})$

$v_{\text {mat }} \quad$ air velocity through clothing $\quad(\mathrm{m} / \mathrm{s})$

$W_{\mathrm{cl}} \quad$ weight of clothing $\quad\left(100 \mathrm{~g} / \mathrm{m}^{2}\right)$

Greek alphabet

$\Psi_{\mathrm{cl}} \quad$ water mass $\quad(\mathrm{kg} / \mathrm{s})$

$\rho \quad$ density of air $\quad\left(\mathrm{kg} / \mathrm{m}^{3}\right)$

$\theta \quad$ angle around cylinder $\quad\left({ }^{\circ}\right)$

$\phi_{\mathrm{v}} \quad$ flow in air gap $\quad\left(\mathrm{m}^{3} / \mathrm{s}\right)$ 